\title{
Stent-Assisted Coil Embolization of Intracranial Aneurysms: Complications in Acutely Ruptured versus Unruptured Aneurysms
}

\author{
(D) R.S. Bechan, (DM.E. Sprengers, (DC.B. Majoie, DJ.P. Peluso, (D) M. Sluzewski, and (DW.J. van Rooij
}

\begin{abstract}
BACKGROUND AND PURPOSE: The use of stents in the setting of SAH is controversial because of concerns about the efficacy and risk of dual antiplatelet therapy. We compare complications of stent-assisted coil embolization in patients with acutely ruptured aneurysms with complications in patients with unruptured aneurysms.
\end{abstract}

\begin{abstract}
MATERIALS AND METHODS: Between February 2007 and March 2015, 45 acutely ruptured aneurysms and 47 unruptured aneurysms were treated with stent-assisted coiling. Patients with ruptured aneurysms were not pretreated with antiplatelet medication but received intravenous aspirin during the procedure. Thromboembolic events and early rebleeds were recorded.

RESULTS: In ruptured aneurysms, 9 of 45 patients had thromboembolic complications. Four patients remained asymptomatic, 4 developed infarctions, and 1 patient died. The permanent complication rate in ruptured aneurysms was $11 \%(95 \% \mathrm{Cl}, 4 \%-24 \%)$. Five of 45 patients (11\%; $95 \% \mathrm{Cl}, 4 \%-24 \%)$ had an early rebleed from the treated aneurysm after 3-45 days, and in 4, this rebleed was fatal. In 46 patients with 47 unruptured aneurysms, thromboembolic complications occurred in 2 . One patient remained asymptomatic; the other had a thalamus infarction. The complication rate in unruptured aneurysms was $2.2 \%$ ( 1 of $46 ; 95 \% \mathrm{Cl}, 0.01 \%-12 \%)$. No first-time hemorrhages occurred in 46 patients with 47 aneurysms during 6 months of follow-up.
\end{abstract}

CONCLUSIONS: The complication rate of stent-assisted coiling with early adverse events in ruptured aneurysms was 10 times higher than that in unruptured aneurysms. Early rebleed accounted for most mortality. In ruptured aneurysms, stent-assisted coil embolization is associated with increased morbidity and mortality and should only be considered when less risky options have been excluded.

$\mathbf{E}$ ndovascular treatment of wide-neck intracranial aneurysms remains a technically challenging procedure due to the risk of coil protrusion into the parent artery and subsequent thrombus formation or parent vessel compromise. There are several techniques to coil wide-neck aneurysms, such as balloon- or stent-assisted coiling, ${ }^{1-7}$ flow diversion, and, more recently introduced, the WEB aneurysm embolization system (Sequent Medical, Aliso Viejo, California). ${ }^{8}$ With the use of stents or flow diverters, complication rates tend to be higher than with selective coiling or balloon-assisted coiling because of the thrombogenicity of the devices and the need for dual antiplatelet medication with inherent risk in the postop-

Received May 18, 2015; accepted after revision July 29

From Sint Elisabeth Ziekenhuis (R.S.B., J.P.P., M.S., W.J.v.R.), Tilburg, the Netherlands; and Academisch Medisch Centrum (M.E.S., C.B.M.), Amsterdam, the Netherlands.

Please address correspondence to Willem Jan van Rooij, MD, Department of Radiology, Sint Elisabeth Ziekenhuis, Hilvarenbeekseweg 60, 5022GC Tilburg, the Netherlands; e-mail: wjjvanrooij@gmail.com

http://dx.doi.org/10.3174/ajnr.A4542 erative period. ${ }^{9-14}$ Most operators are reluctant to use antiplatelet therapy in the setting of subarachnoid hemorrhage because of the potential need for a ventriculostomy, the potential for infarction secondary to vasospasm, and the high likelihood of future invasive interventions. Therefore, stent placement is generally avoided in acutely ruptured aneurysms in favor of clip ligation or other endovascular techniques that do not mandate dual antiplatelet therapy.

In this observational study with prospectively collected data, we evaluated the incidence of hemorrhagic and thromboembolic complications in patients with acutely ruptured aneurysms treated with stent-assisted coiling. In addition, we compared the complication rates with those of unruptured aneurysms treated with stent assistance during the same period.

\section{MATERIALS AND METHODS}

This observational study with prospectively collected data was compliant with institutional privacy policy. The institutional review board gave exempt status for approval and informed consent. 


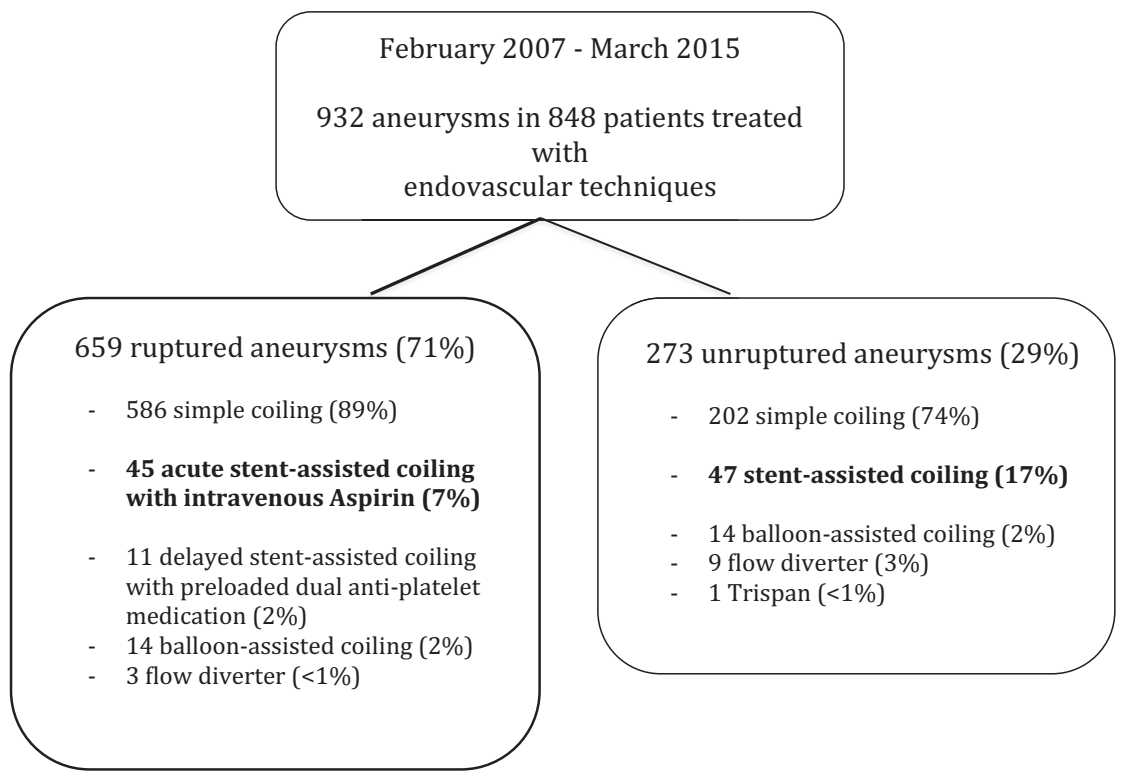

FIG 1. Flow chart of 932 aneurysms in 848 patients treated endovascularly between February 2007 and March 2015.

\section{Patient Population}

Between February 2007 and March 2015, 848 patients with 932 aneurysms were treated with endovascular techniques (Fig 1). There were 659 ruptured aneurysms (71\%) and 273 unruptured aneurysms (29\%). Of 659 ruptured aneurysms, 45 aneurysms in 45 patients were treated with stent-assisted coiling in the acute phase of SAH without pretreatment with antiplatelet medication. Of 273 unruptured aneurysms, 47 in 46 patients were treated with stent-assisted coiling.

\section{General Indications for Stent-Assisted Coiling}

Patients with SAH diagnosed on CT or lumbar puncture underwent angiography of all cerebral vessels on a biplane angiographic system (Integris Allura BN 3000 or Allura FD 20/10; Philips Healthcare, Best, the Netherlands). When a wide-neck ruptured aneurysm (dome-to-neck ratio $<2$ and/or a neck length of $\geq 4$ $\mathrm{mm}$ ) or dissection was identified on 3D angiography, a vascular neurosurgeon was consulted about the best treatment for the individual patient with respect to clinical condition, age, and comorbidities. Stent-assisted coiling in ruptured wide-neck aneurysms was indicated for all aneurysms or dissections located in the posterior circulation and for aneurysms and dissections in the anterior circulation in poor-grade patients who were not surgical candidates.

For unruptured aneurysms, the indications for stent-assisted coiling were determined in a multidisciplinary meeting with neurosurgeons and neurologists.

\section{Stent-Assisted Coiling Procedure}

Coiling was performed with the patient under general anesthesia. First, stent placement was simulated by computer graphics on the 3D dataset by using standard machine software (Philips Healthcare, Best, the Netherlands). ${ }^{15}$ The software exactly calculated the diameters and length of the vessel segment where the stent placement was intended. Accordingly, the proper stent length and di- ameter could be chosen. We aimed at a 10 -mm stent overlap on either side of the aneurysm neck.

The aneurysm was passed with a microcatheter (Prowler Plus; Codman \& Shurtleff, Raynham, Massachusetts). After stent placement, the delivery microcatheter was removed. A new lower profile microcatheter (Excelsior SL-10; Stryker, Kalamazoo, Michigan) was introduced through the stent struts into the aneurysm, and coils were placed until the aneurysm was occluded. In selected cases, a microcatheter was jailed in the aneurysm by the stent.

Of 45 patients, 34 were treated with an Enterprise self-expanding stent (Codman \& Shurtleff); 5, with an Acclino stent (Acandis, Pforzheim, Germany); and 4, with a LVIS stent (MicroVention, Tustin, California). In 2 patients, a LEO stent (Balt Extrusion, Montmorency, France) was used, followed by a Silk flow diverter (Balt Extrusion), which was coaxially placed.

\section{Anticoagulation Protocol}

During coiling of ruptured aneurysms, heparin was administered via the pressure bags ( $1000 \mathrm{U}$ per $500 \mathrm{~mL}$ of saline). Intravenous aspirin, $500 \mathrm{mg}$, was administered immediately before stent placement. ${ }^{14}$ After the procedure, patients were prescribed a loading dose of $300 \mathrm{mg}$ of clopidogrel (Plavix), followed by $75 \mathrm{mg}$ of clopidogrel daily for 6 months and, life-long, $80 \mathrm{mg}$ of aspirin daily. The clopidogrel loading dose was administered orally or through a gastric tube immediately after the procedure. For 48 hours after the procedure, $7500 \mathrm{U}$ of subcutaneous heparin was given twice daily.

Patients with unruptured aneurysms were preloaded for 4 days with clopidogrel and aspirin and were heparinized during the procedure. Dual antiplatelet therapy was continued for 6 months; and aspirin, $80 \mathrm{mg}$ daily, life-long. Response to antiplatelet therapy was not tested before the procedure.

When a thromboembolic event (angiographically visible thrombus or vessel occlusion) occurred during the endovascular procedure, a loading dose of glycoprotein IIb/IIIa antagonist (tirofiban [Aggrastat]) was administered intravenously or intraarterially followed by drip infusion for 24 hours. In 1 patient, mechanical thrombectomy with a Solitaire stent (Covidien, Irvine, California) was performed. The decision to perform a thrombectomy depended on the location of the thrombus, and the perception of possible successful removal.

\section{Clinical and Imaging Outcomes}

Procedural complications were defined as visible thrombus or vessel occlusion during the procedure or procedural rupture. Clinical consequences of thromboembolic complications were recorded. If the clinical condition of the patient worsened after the procedure, CT or MR imaging was performed to clarify the cause. In patients with an early rebleed, control angiography was per- 

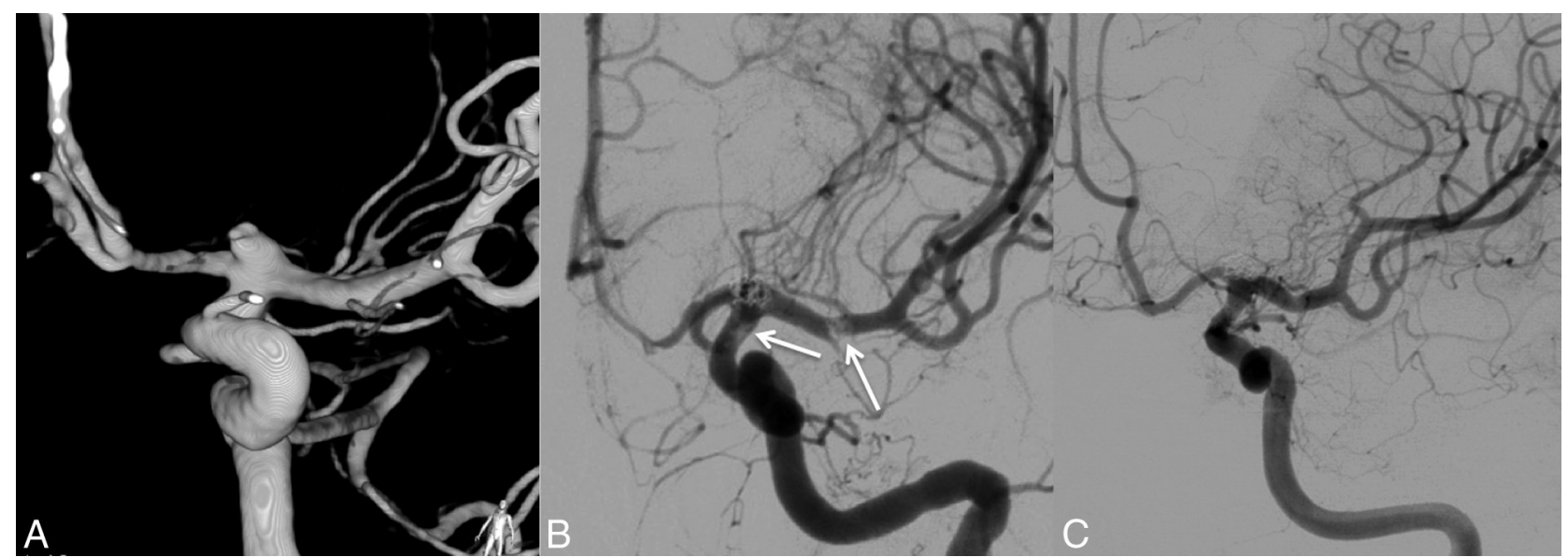

FIG 2. Ruptured carotid tip aneurysm in a 58-year-old woman treated with stent-assisted coiling. $A$, 3D angiogram shows a wide-neck aneurysm on the carotid tip. $B$, Anteroposterior left carotid artery angiogram during coiling demonstrates thrombus formation on the proximal and distal ends of the stent (arrows). C, Follow-up angiogram at 6 months shows complete aneurysm occlusion and patent distal internal carotid and middle cerebral arteries.

formed if the clinical condition was fair or good. In patients with a thromboembolic complication, a native CT and diffusionweighted MR imaging were performed.

For all other surviving patients, a follow-up visit, including angiography or MRA imaging, was scheduled at 6 months. The outcome was assessed according to the mRS scale. Extended imaging follow-up was tailored to the individual patient.

Additional coiling was scheduled in cases in which the aneurysm was reopened by coil compaction or resolution of intraluminal thrombus.

\section{Statistical Analysis}

Quantitative variables were expressed with descriptive statistics, and categoric variables were expressed as frequencies or percentages with 95\% CIs. The $\chi^{2}$ test was used for comparison of proportions. Statistical analysis was performed with MedCalc for Windows, Version 14.12.0 (MedCalc Software, Mariakerke, Belgium).

\section{RESULTS}

\section{Patients with Ruptured Aneurysms}

Forty-five patients with 45 ruptured aneurysms were treated with stent-assisted coiling. There were 33 women (75\%) and 12 men (25\%), with a mean age of 56 years (median, 58 years; range, 21-79 years). Aneurysm location was the basilar tip in 13, anterior communicating artery in 8 , carotid tip in 6 , middle cerebral artery in 4 , vertebral artery in 4 , posterior communicating artery in 2, supraclinoid dissection aneurysm in 2, superior cerebellar artery in 2, basilar trunk in 2, A1 in 1, and PICA dissection in 1. The mean aneurysm size was $8.7 \mathrm{~mm}$ (median, $7 \mathrm{~mm}$; range, 2-30 $\mathrm{mm})$. The clinical condition at the time of treatment according to the Hunt and Hess scale (HH) was HH 1-2 in 6 (13\%), HH 3 in 21 (47\%), and HH 4-5 in 18 (40\%). Timing of stent-assisted coiling after SAH was a mean of 1.7 days (median, 1 day; range, $0-11$ days). Of 45 patients, 36 (80\%) were treated within 24 hours after the onset of SAH.

Procedural Complications. Nine patients had thromboembolic complications. In 3 patients with angiographically visible thrombus on the stent without vessel occlusion and tirofiban treatment, this complication remained without clinical symptoms (Fig 2). In 1 patient with an anterior communicating artery aneurysm, thrombus occluded the middle cerebral artery, mechanical thrombectomy was successful, and the outcome was good.

In 3 patients with visible in-stent thrombus, infarctions developed despite tirofiban treatment (Fig 3). One patient with a basilar tip aneurysm developed an infarction in the posterior cerebral artery after the procedure. One patient with a basilar tip aneurysm died of progressive basilar thrombosis during the procedure.

There were no procedural ruptures.

The overall procedure-related complication rate was $11 \%$ (5 of 45 ; $95 \%$ CI, 4\%-24\%).

Early Rebleed from the Coiled Aneurysm. Five of 45 patients (11\%; 95\% CI, 4\%-24\%) had an early rebleed from the treated aneurysm after 3, 12, 26, 32, and 45 days (Table). Four of these aneurysms seemed completely occluded (Fig 4), and 1 was incompletely occluded. In 4 of 5 patients, this rebleed was fatal; 1 patient had a good outcome (mRS 2). All 5 recurrent hemorrhages were from saccular aneurysms.

Additional Surgical Procedures. Ten patients underwent external ventricular drainage, 7 before and 3 after stent-assisted coiling. One patient had an external lumbar drain; and 1, a lumboperitoneal drain after coiling. Two patients underwent a decompressive hemicraniectomy. There were no hemorrhagic complications from surgical procedures and no additional clipping after stent-assisted coiling.

Overall Clinical and Imaging Outcome in Patients with Ruptured Aneurysms. Immediate postprocedural angiography showed adequate (complete or near-complete) aneurysm occlusion in 42 patients (93\%), and incomplete occlusion in $3(7 \%)$.

At 6 months' follow-up, 13 patients (29\%) had died (mRS 6): Seven patients died of the sequelae of SAH; 1, of a thromboembolic complication; 4 , of a rebleed; and 1, of a traumatic subdural hematoma at 5 months. A good outcome (mRS 0-1) 


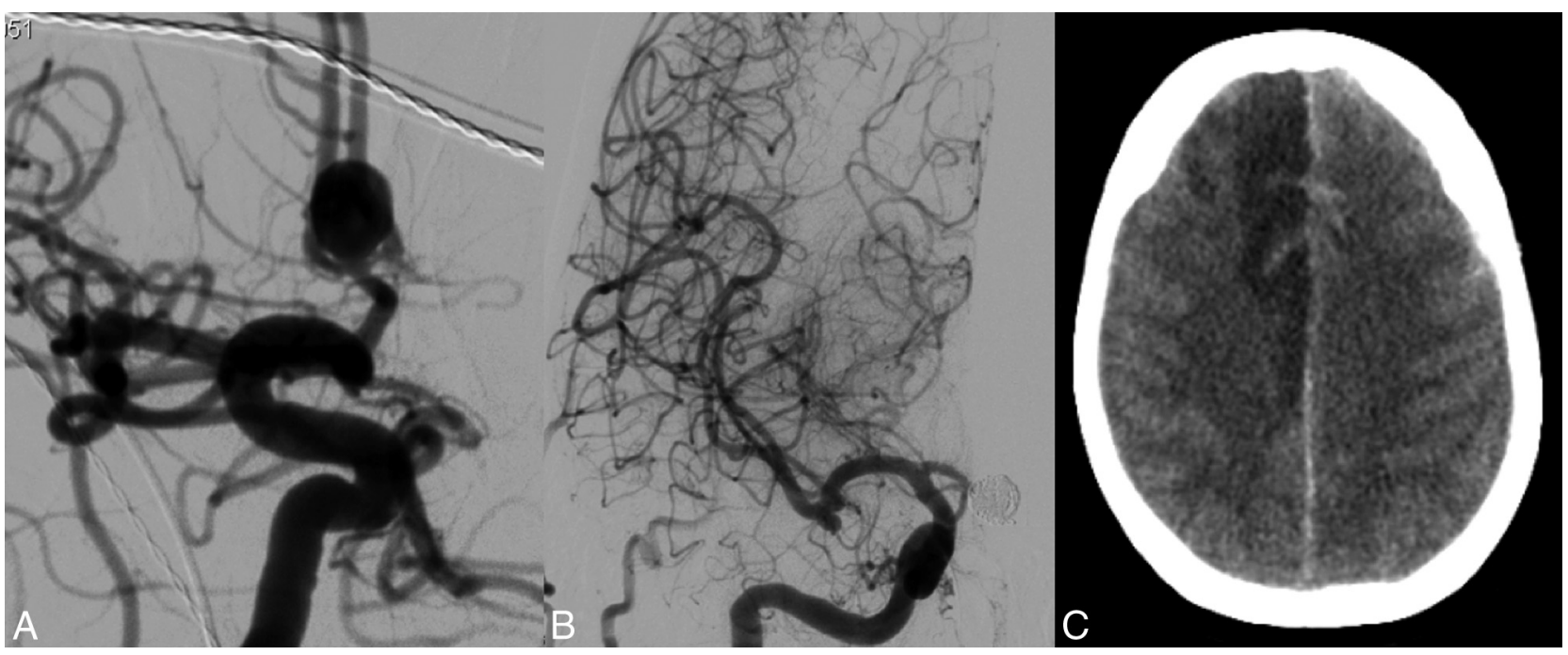

FIG 3. Ruptured anterior communicating artery aneurysm in a 64-year-old woman. A, Anteroposterior right carotid artery angiogram shows a large anterior communicating artery aneurysm with a relatively wide neck. A stent was placed in the right Al-A2. B, After coiling, the right A2 was completely occluded by an in-stent thrombus that did not react to glycoprotein Ilb/llla antagonist (tirofiban) therapy. C, CT scan the next day demonstrates infarction in the right anterior cerebral artery territory.

Characteristics of 5 patients with an early rebleed after stent-assisted coiling of a ruptured aneurysm

\begin{tabular}{cclllcc}
\hline $\begin{array}{c}\text { Patient Sex, } \\
\text { Age (yr) }\end{array}$ & $\begin{array}{c}\text { HH } \\
\text { Grade }\end{array}$ & $\begin{array}{c}\text { Aneurysm Location } \\
\text { and Size }\end{array}$ & $\begin{array}{c}\text { Occlusion } \\
\text { Rate }\end{array}$ & Stent & $\begin{array}{c}\text { Timing of } \\
\text { Rebleed }\end{array}$ & Outcome \\
\hline F, 48 & 3 & PcomA, $4 \mathrm{~mm}$ & Complete & Enterprise & 45 Days & Death \\
F, 58 & 3 & SCA, 3 mm & Complete & Enterprise & 12 Days & Death \\
F, 64 & 4 & Carotid tip, $5 \mathrm{~mm}$ & Incomplete & Enterprise & 32 Days & Death \\
F, 70 & 1 & Basilar trunk, 30 mm & Complete & LEO & 26 Days & Death \\
F, 54 & 5 & MCA, $11 \mathrm{~mm}$ & Complete & LVIS & 3Days & mRS2 \\
\hline
\end{tabular}

Note:-PcomA indicates posterior communicating artery; SCA, superior cerebellar artery; HH, Hunt and Hess.
95\% CI, $0.01 \%-12 \%)$. No first-time hemorrhages occurred in 46 patients with 47 aneurysms during 6 months of follow-up.

\section{Comparison of Complications in Ruptured and Unruptured Aneurysms}

In patients who underwent stent-assisted coiling in the acute period of $\mathrm{SAH}$, the symptomatic complication rate due to this strategy was $22.2 \%$ ( 10 of 45 ), and

was achieved in 24 patients (53\%), 6 patients had some disability (mRS $2-3$ ), and 2 patients were in a nursing home (mRS 5).

Angiographic (9 patients) or MR imaging follow-up (20 patients) was a mean of 18 months (median, 6 months; range, 6-75 months) in 29 of 30 eligible patients; 1 patient is scheduled for MRA. Reopening of the aneurysm was evident in 6 patients (21\%), and these aneurysms were additionally coiled. The other 23 aneurysms remained completely occluded. In 1 asymptomatic patient $(3 \%)$ with a small carotid tip aneurysm, the A1 showed progressive and severe narrowing by intimal hyperplasia after 1 year (Fig 5).

\section{Patients with Unruptured Aneurysms}

Forty-six patients with 47 unruptured aneurysms were treated with stent-assisted coiling. There were 34 women (74\%) and 12 men $(26 \%)$ with a mean age of 58.4 years (median, 59 years; range, 27-80 years). Aneurysm size was a mean of $13 \mathrm{~mm}$ (median, 11 $\mathrm{mm}$; range, 3-40 mm). Twenty-four aneurysms (51\%) were located in the anterior circulation, and 23 (49\%), in the posterior circulation.

Thromboembolic complications occurred in 2 patients (4\%). One patient responded favorably to tirofiban. The other patient (with a 12-mm basilar tip aneurysm) developed hemiparesis and an infarction in the left thalamus. At 6 months' follow-up, the hemiparesis had improved (outcome mRS of 2). Mortality was $0 \%$ ( 0 of $46 ; 95 \%$ CI, $0 \%-9.2 \%$ ), and morbidity was $2.2 \%$ ( 1 of 46 ; in unruptured aneurysms, it was $2.2 \%$ ( 1 of 46 ). This difference was highly significant $(P=.001)$.

\section{DISCUSSION}

In this study, we found that the complication rate with early adverse events of stent-assisted coiling in patients with ruptured aneurysms was very high and 10 times higher than that in stent-assisted coiling of unruptured aneurysms. The high frequency of early rebleeds (11\%, 5 of 45$)$ accounted for the high mortality: In 4 of 5 patients, the rebleed was fatal. In 2 of 5 patients with angiography shortly after the rebleed, the aneurysm seemed completely occluded (Fig 4). Apparently, in these patients, the anticoagulation medication prevented thrombosis of the aneurysm in the days following coiling, despite adequate packing with coils.

$\mathrm{SAH}$ in the acute period triggers the coagulation cascade, leading to a hypercoagulable state with a high tendency for clotting or thrombosis. Heparinization in combination with intravenous aspirin did not prevent thrombus formation (on the stent) in all cases: Thromboembolic complications occurred in $20 \%$ (9 of 45) with permanent neurologic deficits in 4 and death in 1 patient. Tirofiban was administered in those patients with visible thrombus during the procedure. In our study, 3 of 6 patients with visible thrombus had successful 


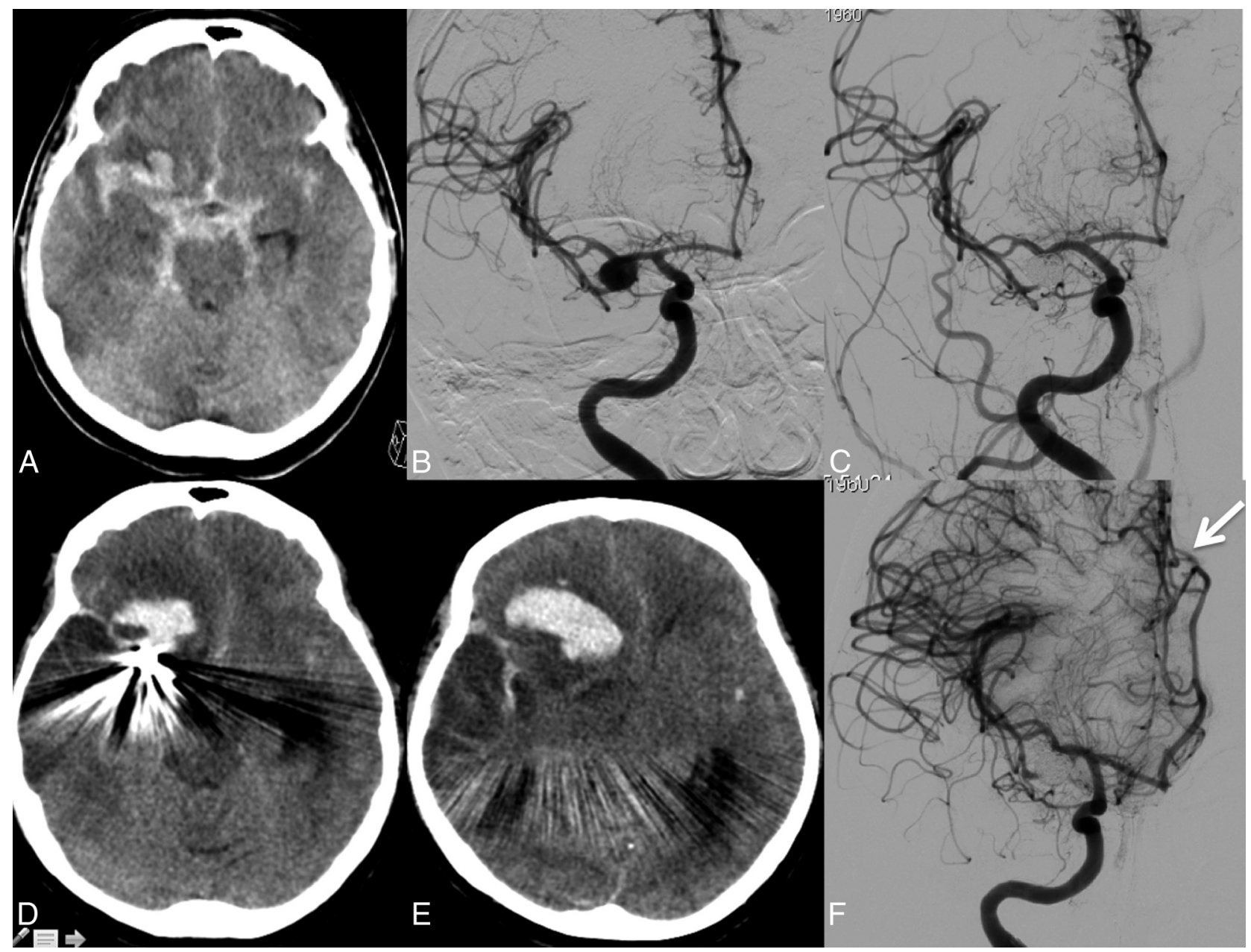

FIG 4. Ruptured middle cerebral artery aneurysm in a 54-year-old woman. $A, C T$ scan on admission with SAH from the right middle cerebral artery aneurysm. $B$, Anteroposterior carotid artery angiogram shows a wide-neck middle cerebral artery aneurysm. $C$, Angiogram after stentassisted coiling demonstrates complete aneurysm occlusion. $D$ and $E, C T$ scan 3 days later reveals recurrent hemorrhage from the aneurysm. $F$, Repeat angiogram the same day confirms complete occlusion of the aneurysm. Note subfalcine herniation of the anterior cerebral artery resulting from a large hematoma (arrow).

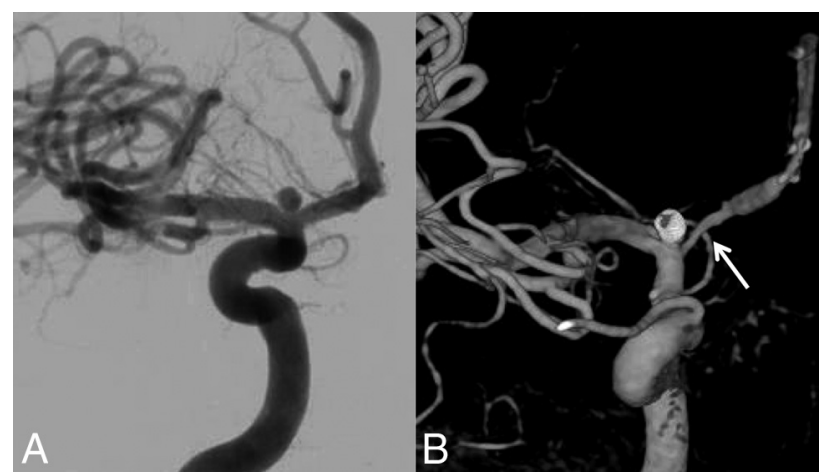

FIG 5. Ruptured small carotid tip aneurysm in a 33-year-old man. $A$, Anteroposterior carotid angiogram shows the small carotid tip aneurysm. A coil was placed inside the aneurysm, which seemed unstable, and a stent was subsequently placed across the neck in the A1. B, 3D angiogram 1 year later demonstrates severe narrowing of the Al. The patient was asymptomatic.

recanalization after treatment with tirofiban and had a good clinical outcome.

Our disappointing results are in concordance with those in other studies. Chalouhi et al ${ }^{4}$ also concluded, from a study of 508 patients, that stent-assisted coiling of ruptured aneurysms was associated with higher complication rates (25\% versus $4.7 \%)$ and worse outcomes. The morbidity-mortality rate in this study was $13 \%$ in patients with a ruptured aneurysm.

Ruptured aneurysms were also independently predictive of complications and poor outcomes in several other studies. ${ }^{5,6,10}$ Thus, the safety-efficacy profile of stent-assisted coiling is clearly less favorable in ruptured than in unruptured aneurysms.

Hemorrhagic complications consistently contributed the most to morbidity and mortality rates. In addition to the frequent early rebleeds from the ruptured aneurysms treated with stentassisted coiling, as seen in our study and others, ${ }^{1,9,11}$ fatal hemorrhagic complications may also occur from extraventricular drain placement or even spontaneous remote intracranial hemorrhages. ${ }^{9,12}$ Apparently, with dual antiplatelet therapy, coiling does not protect against rebleed and induces hemorrhages from surgical procedures.

In addition to the complications in the periprocedural period, delayed complications may also occur ${ }^{7,16,17}$ : In a follow-up study of 213 patients by Mocco et al, ${ }^{16} 6$ percent of patients had delayed (>30 days) angiographic adverse findings, of which, 3\% demon- 
strated high-grade in-stent stenosis or occlusion. Seven delayed thromboembolic events occurred (3\%), along with 2 additional immediate periprocedural events. All 7 delayed events occurred after cessation of dual-antiplatelet therapy. Longer follow-up studies are needed to better understand the long-term effects of stents on the intracranial vasculature.

Our data and those of others indicate that stent-assisted coiling in the acute phase of SAH is associated with many procedural and postprocedural complications, thromboembolic, hemorrhagic, and delayed. In our opinion, this type of therapy and its indications should be reconsidered to significantly decrease the complication rate. We have some suggestions. First, direct surgical clipping can be a valuable and low-risk alternative for coiling in good-grade patients with ruptured wide-neck aneurysms in the anterior circulation. Second, in ruptured wide-neck posterior circulation aneurysms and in poor-grade patients with ruptured wide-neck aneurysms in the anterior circulation, balloon assistance obviates antiplatelet medication and should be preferred over stent placement. Third, the recent introduction of the WEB device ${ }^{8}$ is a promising alternative treatment to stent-assisted coiling for wide-neck ruptured aneurysms without the need for antiplatelet medication.

Our study is limited by its absence of randomization between study groups. The results reflect the experience of a single neurovascular center with a specific technique and anticoagulation protocols and may not be readily generalizable to other centers. The individual response to antiplatelet medication was not tested. Because diffusion-weighted imaging was not routinely performed, the incidence of clinically silent infarcts has likely been underestimated. MRA was used in most patients eligible for imaging follow-up. MRA is sufficient to detect reopening, hemorrhage, and infarction but has limitations in detecting in-stent stenosis.

Despite these limitations, this study confirms that stent-assisted coiling in the acute phase in ruptured aneurysms is associated with a high complication rate.

\section{CONCLUSIONS}

In acutely ruptured wide-neck aneurysms treated with stent-assisted coiling, antiplatelet medication without pretreatment does not prevent all thromboembolic complications and, in addition, is a risk factor for hemorrhagic complications in the periprocedural period. Therefore, this treatment should be avoided in favor of other surgical or endovascular treatments without the need for antiplatelet medication.

Disclosures: Charles B. Majoie-UNRELATED: Grants/Grants Pending: Dutch Heart Foundation*; Payment for Lectures (including service on Speakers Bureaus): Stryker (payment for lectures).* *Money paid to the institution.

\section{REFERENCES}

1. Bodily KD, Cloft HJ, Lanzino G, et al. Stent-assisted coiling in acutely ruptured intracranial aneurysms: a qualitative, systematic review of the literature. AJNR Am J Neuroradiol 2011;32:1232-36 CrossRef Medline

2. Shapiro M, Becske T, Sahlein D, et al. Stent-supported aneurysm coiling: a literature survey of treatment and follow-up. AJNR Am J Neuroradiol 2012;33:159-63 CrossRef Medline

3. Mocco J, Snyder KV, Albuquerque FC, et al. Treatment of intracranial aneurysms with the Enterprise stent: a multicenter registry. J Neurosurg 2009;110:5-39 CrossRef Medline

4. Chalouhi N, Jabbour P, Singhal S, et al. Stent-assisted coiling of intracranial aneurysms: predictors of complications, recanalization, and outcome in $\mathbf{5 0 8}$ cases. Stroke 2013;44:1348-53 CrossRef Medline

5. Piotin M, Blanc R, Spelle L, et al. Stent-assisted coiling of intracranial aneurysms: clinical and angiographic results in 216 consecutive aneurysms. Stroke 2010;41:110-15 CrossRef Medline

6. Wakhloo AK, Linfante I, Silva CF, et al. Closed-cell stent for coil embolization of intracranial aneurysms: clinical and angiographic results. AJNR Am J Neuroradiol 2012;33:1651-56 CrossRef Medline

7. Biondi A, Janardhan V, Katz JM. Neuroform stent-assisted coil embolization of wide-necked intracranial aneurysms: strategies in stent deployment and midterm follow-up. Neurosurgery 2007;61: 460-68; discussion 468-69 CrossRef Medline

8. Behme D, Berlis A, Weber W. Woven EndoBridge intrasaccular flow disrupter for the treatment of ruptured and unruptured wide-neck cerebral aneurysms: report of 55 cases. AJNR Am J Neuroradiol 2015; 36:1501-06 CrossRef Medline

9. Chung J, Lim YC, Suh SH, et al. Stent-assisted coil embolization of ruptured wide-necked aneurysms in the acute period: incidence of and risk factors for periprocedural complications. J Neurosurg 2014; 121:4-11 CrossRef Medline

10. Tähtinen OI, Vanninen RL, Manninen HI, et al. Wide-necked intracranial aneurysms: treatment with stent-assisted coil embolization during acute ( $<72$ hours) subarachnoid hemorrhage: experience in 61 consecutive patients. Radiology 2009;253:199-208 CrossRef Medline

11. Amenta PS, Dalyai RT, Kung D, et al. Stent-assisted coiling of widenecked aneurysms in the setting of acute subarachnoid hemorrhage: experience in 65 patients. Neurosurgery 2012;70:141529; discussion 1429 CrossRef Medline

12. Tumialán LM, Zhang YJ, Cawley CM, et al. Intracranial hemorrhage associated with stent-assisted coil embolization of cerebral aneurysms: a cautionary report. J Neurosurg 2008;108:1122-29 CrossRef Medline

13. Brinjikji W, Morales-Valero SF, Murad MH, et al. Rescue treatment of thromboembolic complications during endovascular treatment of cerebral aneurysms: a meta-analysis. AJNR Am J Neuroradiol 2015;36:121-25 CrossRef Medline

14. Ries T, Buhk JK, Kucinski T, et al. Intravenous administration of acetylsalicylic acid during endovascular treatment of cerebral aneurysms reduces the rate of thromboembolic events. Stroke 2006;37: 1816-21 CrossRef Medline

15. Peluso JP, van Rooij WJ, Sluzewski M, et al. A new self-expandable nitinol stent for the treatment of wide-neck aneurysms: initial clinical experience. AJNR Am J Neuroradiol 2008;29:1405-08 CrossRef Medline

16. Mocco J, Fargen KM Albuquerque FC, et al. Delayed thrombosis or stenosis following Enterprise-assisted stent-coiling: is it safe? Midterm results of the interstate collaboration of Enterprise stent coiling. Neurosurgery 2011;69:908-13; discussion 913-14 CrossRef Medline

17. Fiorella D, Albuquerque FC, Woo H. Neuroform in-stent stenosis: incidence, natural history, and treatment strategies. Neurosurgery 2006;59:34-42; discussion 34-42 CrossRef Medline 